\title{
Interventions for stimulus deprivation amblyopia (Review)
}

\author{
Antonio-Santos A, Vedula SS, Hatt SR, Powell C
}

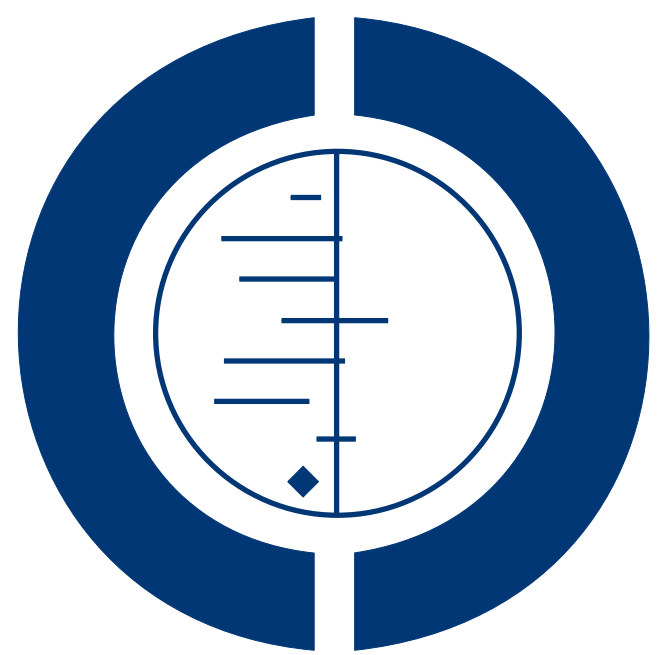

THE COCHRANE COLLABORATION $^{\circledR}$

This is a reprint of a Cochrane review, prepared and maintained by The Cochrane Collaboration and published in The Cochrane Library 2006, Issue 3

http://www.thecochranelibrary.com

\section{WILEY}

Interventions for stimulus deprivation amblyopia (Review)

Copyright $\odot 2009$ The Cochrane Collaboration. Published by John Wiley \& Sons, Ltd. 
TABLE OF CONTENTS

HEADER . . . . . . . . . . . . . . . . . . . . . . . . . . . . . . . . . . . . 1

ABSTRACT . . . . . . . . . . . . . . . . . . . . . . . . . . . . . . . . . . . . . . . . . . . . . . .

PLAIN LANGUAGE SUMMARY . . . . . . . . . . . . . . . . . . . . . . . . . . . . . . . . . . . 2

BACKGROUND . . . . . . . . . . . . . . . . . . . . . . . . . . . . . . . . . . . . . . . . .

OBJECTIVES . . . . . . . . . . . . . . . . . . . . . . . . . . . . . . . . . . . . .

METHODS . . . . . . . . . . . . . . . . . . . . . . . . . . . . . . . . . . . . . .

RESULTS . . . . . . . . . . . . . . . . . . . . . . . . . . . . . . . . . . 7

DISCUSSION . . . . . . . . . . . . . . . . . . . . . . . . . . . . . . . . . . . . .

AUTHORS' CONCLUSIONS . . . . . . . . . . . . . . . . . . . . . . . . . . . . . . . . . . . . . . . . . .

ACKNOWLEDGEMENTS . . . . . . . . . . . . . . . . . . . . . . . . . . . . . . . . . 9

REFERENCES . . . . . . . . . . . . . . . . . . . . . . . . . . . . . . . . . . . . . . 10

CHARACTERISTICS OF STUDIES . . . . . . . . . . . . . . . . . . . . . . . . . . . . . . . . . . . . . .

DATA AND ANALYSES . . . . . . . . . . . . . . . . . . . . . . . . . . . . . . . . . . . . 16

APPENDICES . . . . . . . . . . . . . . . . . . . . . . . . . . . . . . . . . . . . 16

WHAT'S NEW . . . . . . . . . . . . . . . . . . . . . . . . . . . . . . . . . . . . . . 18

HISTORY . . . . . . . . . . . . . . . . . . . . . . . . . . . . . . . . . . . . . . . 19

CONTRIBUTIONS OF AUTHORS . . . . . . . . . . . . . . . . . . . . . . . . . . . . . . . . . . . . 19

DECLARATIONS OF INTEREST . . . . . . . . . . . . . . . . . . . . . . . . . . . . . . . .

SOURCES OF SUPPORT . . . . . . . . . . . . . . . . . . . . . . . . . . . . . . . . . . . . . . . . . .

INDEX TERMS . . . . . . . . . . . . . . . . . . . . . . . . . . . . . . . . . . . . . 20

Interventions for stimulus deprivation amblyopia (Review)

Copyright $\odot 2009$ The Cochrane Collaboration. Published by John Wiley \& Sons, Ltd. 


\title{
[Intervention Review]
}

\section{Interventions for stimulus deprivation amblyopia}

\author{
Aileen Antonio-Santos ${ }^{1}$, Satyanarayana S Vedula ${ }^{2}$, Sarah R Hatt ${ }^{3}$, Christine Powell ${ }^{4}$ \\ ${ }^{1}$ Department of Neurology and Ophthalmology, Michigan State University, East Lansing, Ingham, USA. ${ }^{2}$ Cochrane Eyes and Vision \\ Group US Project, Johns Hopkins Bloomberg School of Public Health, Baltimore, MD, USA. ${ }^{3}$ Ophthalmology Research, Mayo Clinic, \\ Rochester, USA. ${ }^{4}$ Department of Ophthalmology, Royal Victoria Infirmary, Newcastle upon Tyne, UK \\ Contact address: Aileen Antonio-Santos, Department of Neurology and Ophthalmology, Michigan State University, A217, Clinical \\ Center, 138 Service Road, East Lansing, Ingham, MI 48824, USA. aileen.antonio@ht.msu.edu .
}

Editorial group: Cochrane Eyes and Vision Group.

Publication status and date: Edited (no change to conclusions), published in Issue 1, 2009.

Review content assessed as up-to-date: 26 November 2007.

Citation: Antonio-Santos A, Vedula SS, Hatt SR, Powell C. Interventions for stimulus deprivation amblyopia. Cochrane Database of Systematic Reviews 2006, Issue 3. Art. No.: CD005136. DOI: 10.1002/14651858.CD005136.pub2.

Copyright (C) 2009 The Cochrane Collaboration. Published by John Wiley \& Sons, Ltd.

\begin{abstract}
A B S T R A C T
Background

Stimulus deprivation amblyopia (SDA) develops due to an obstruction to the passage of light, preventing clear formation of an image on the retina (e.g. cataract, ptosis). It is particularly severe and can be resistant to treatment, leading to poor visual prognosis. Precise estimates of SDA prevalence are difficult to come by but it probably constitutes less than $3 \%$ of all amblyopia cases. In developed countries, most patients present under the age of one; in less developed parts of the world, presentation is likely to be significantly later than this. The mainstay of treatment is occlusion of the better-seeing eye, but regimens vary, can be difficult to execute and are traditionally believed to lead to disappointing results.
\end{abstract}

\section{Objectives}

The objectives of this review were to evaluate the effectiveness of occlusion treatment for SDA, to establish the optimum treatment regimen, to determine the factors that may affect outcome, and to identify realistic treatment goals.

\section{Search methods}

We searched the Cochrane Central Register of Controlled Trials - CENTRAL (which contains the Cochrane Eyes and Vision Group Trials Register) in The Cochrane Library (Issue 4, 2007), MEDLINE (1996 to November 2007), EMBASE (1980 to November 2007) and the Latin American and Caribbean Literature on Health Sciences (LILACS) (November 2007). The electronic databases were last searched on 27 November 2007. There were no date or language restrictions.

\section{Selection criteria}

Randomized and quasi-randomized controlled trials of participants with unilateral SDA, with visual acuity worse than 0.2 LogMAR or equivalent, were to be included. There were no restrictions with respect to age, gender, ethnicity, co-morbidities, medication use, and the number of participants.

\section{Data collection and analysis}

Two review authors independently assessed study abstracts identified by the electronic searches.

\section{Main results}

No trials were identified that met the inclusion criteria.

Interventions for stimulus deprivation amblyopia (Review)

Copyright @ 2009 The Cochrane Collaboration. Published by John Wiley \& Sons, Ltd. 


\section{Authors' conclusions}

It is not possible to conclude how effective SDA treatment is or which treatment regimen produces the best results. There is a need for further study in this area.

\section{PLAIN LANGUAGE SUMMARY}

\section{Treatment for amblyopia caused by obstructed vision in early childhood}

Amblyopia or 'lazy eye' occurs when vision does not develop normally in early childhood. This may be due to strabismus, anisometropia (unequal refractive error) or obstruction of vision. Stimulus deprivation amblyopia (SDA), the type examined in this review, develops due to obstruction of vision in early childhood by conditions such as cataract (cloudy lens) or ptosis (droopy eyelid). Stimulus deprivation amblyopia is generally accepted to be the hardest type of amblyopia to treat. The prevalence of amblyopia varies from $1 \%$ to $5 \%$, with SDA constituting less than $3 \%$ of all amblyopia cases. Health professionals or parents initially detect the accompanying signs of visual obstruction (e.g. leukocoria - whitish pupil associated with congenital cataract, droopy eyelid) when the patient is under the age of one. Amblyopia is then diagnosed after the causative factor has been treated and refractive correction has been given. The level of vision taken to be below normal varies; for this review, it was operationally defined as vision below $0.2 \operatorname{LogMAR}$ or its equivalent, although typically the level of loss in SDA is much more severe. The aim of amblyopia treatment is to maximize visual recovery without adversely affecting the better-seeing eye. The rationale is to provide a good second eye should the better eye ever lose vision and to maximize stereopsis (binocular vision). Patching the better-seeing eye is the mainstay of treatment and amblyopia treatment is only effective in early childhood. Optimum treatment is unclear and prescribed regimens therefore vary. Reports of treatment success are inconsistent. Occlusion can be harrowing for parents and stressful for the child, making compliance an issue. Untreated or unsuccessfully treated amblyopia may affect employment in adult life. The aim of the review was to examine existing evidence to help establish realistic treatment outcomes and to determine the most effective treatment regimen(s). We searched for randomized controlled trials examining the effectiveness of patching or other treatment strategies for SDA, but did not find any that fulfilled our inclusion criteria. There remains a pressing need for better evidence of treatment effectiveness for this condition.

\section{B A C K G R O U N D}

\section{Description of the condition}

Amblyopia derives from the Greek words "amblys" meaning blunt and "ops" meaning eye, thus bluntness of vision. Clinically, amblyopia denotes a reduction in vision in the absence of any retinal anomaly and any disorder of the afferent visual pathways (Duke-Elder 1973). Amblyopia can be bilateral, but is most commonly unilateral. Amblyopia is usually classified according to its cause:

- strabismic: as a result of squint (eye misalignment);

- anisometropic: unequal refractive (focusing) error;

- meridional: due to astigmatism (irregular corneal curvature);

- ammetropic: high refractive error in both eyes;

- stimulus deprivation: secondary to an obstruction in the anterior visual pathway.
Where more than one cause exists, it will often be described as mixed amblyopia; typically this is a combination of strabismic and anisometropic amblyopia. This review only appraised unilateral stimulus deprivation amblyopia (SDA); interventions for other types of amblyopia are currently being evaluated in a series of separate Cochrane reviews (Shotton 2005; Shotton 2008).

\section{Pathophysiology}

The organization of the adult visual cortex (brain) is determined by early visual experiences (Wiesel 1963). The time within which abnormal visual input can lead to a disruption of the normal pattern of development is called the 'critical period' (Hockfield 1998). There are several critical periods, each associated with different visual functions (Harwerth 1990), which probably reflect development of different parts of the brain. These critical periods do not end abruptly and can be considered as a continuum from extreme sensitivity to almost no sensitivity to external stimuli. Amblyopia finds its roots in these critical periods at young ages when the brain 
and visual system are immature and connections between neurons are still being formed and stabilized. During the critical period, amblyopia is reversible, usually until the child is eight years old; this period of plasticity varies considerably among children and depends on the type of amblyopia.

\section{Etiology}

Stimulus deprivation amblyopia, also known as amblyopia ex anopsia, refers to the type of amblyopia where loss of vision results from disuse or lack of formation of clear retinal images, most commonly as a result of one of the following:

- unoperated infantile cataract (opacity of the lens);

- ptosis (droopy lid) (Dray 2002; Gusek 2000);

- hemangioma (blood-rich swelling on the lid) (Schulz 1982);

- vitreous hemorrhages (bleeding into the clear gel that fills the eye) (Ferrone 1994) or other obstructions in the vitreous such as persistent hyperplastic primary vitreous (PHPV);

- aphakia (absence of the natural lens);

- occlusion prescribed to treat amblyopia of the other eye (Awaya 1973; Von Noorden 1973; Von Noorden 1981).

The eye itself may be otherwise heal thy or in some cases, there is coexisting pathology such as microphthalmos (small eye), coloboma (incomplete formation of the eye), optic nerve hypoplasia (underdeveloped optic nerve) or retinal abnormality. It can be very difficult to discern the extent of visual loss that is due to the amblyopia and what is due to other pathology. Co-existing disease will often limit the visual prognosis, making treatment harder to manage. The most commonly reported cause of SDA is unilateral congenital or infantile cataract. The affected eye is subjected to stimulus deprivation secondary to the cataract until the cataract is removed; stimulus deprivation continues until optical correction is provided. The aphakic eye may continue to be subjected to anisometropia and anisekonia (unequal image size) even after optical correction (Enoch 1983). The early insult to the visual system seems to make this type of amblyopia particularly severe and resistant to treatment. The visual prognosis is reported to be poor (Kanski 1994; Taylor 1997).

\section{Epidemiology}

The prevalence of amblyopia in the general population ranges from $1 \%$ to 5\% (Brown 2000; Hillis 1983). In European children, the prevalence ranges from $1 \%$ to $2.5 \%$ (Kvarnstrom 2001; Newman 2000). Amblyopia accounts for $29 \%$ of unilateral blindness in Copenhagen (Buch 2001) and as much as $8.3 \%$ of bilateral blindness in India following childhood cataract surgery (Dandona 2003). Stimulus deprivation amblyopia is seen in less than $3 \%$ of amblyopic patients (Hillis 1983). There is no known age, gender, race, or developing-developed country differences. These differences may also be due to varying definitions of amblyopia used in the studies.

\section{Presentation}

Routine health checks of babies and toddlers are carried out by a variety of health care personnel (e.g. pediatricians, nurses) and provide an opportunity for detection of the causative signs (e.g. ptosis, cataract) associated with SDA. However provision of such screening is not universal. Access to health care professionals and services may be limited, especially in the rural areas of developing countries. Stimulus deprivation amblyopia itself is not likely to be noticed, but parents may detect the signs associated with the cause of SDA such as leukocoria (whitish pupils) with congenital cataracts or the droopy eyelid (ptosis). Once poor vision in one eye is established, strabismus or squint (misalignment) may develop which may lead to a referral. In the developed world, most patients present for treatment while they are under a year old (Mein 1991); this is likely to be significantly later where healthcare is limited.

\section{Diagnosis}

There are four main steps in the diagnosis of SDA.

(1) Visual acuity testing. Testing young children is largely reliant on objective observations that are limited by cognition and concentration. Qualitative methods (e.g. assessing fixation preference) may be used. However, quantitative tests (e.g. preferential looking) are more precise. Preferential looking tests rely on the observation that infants prefer to look at patterned rather than plain surfaces (Fanz 1958). If the child can discern the striped panel on the card presented, he will look at it. The degree of visual angle subtended by the stripes is known; therefore, a Snellen equivalent can be calculated. In older children, testing methods are more objective, relying on the child identifying pictures or letter optotypes in Snellen, decimal or LogMAR notation.

(2) External and internal eye examination to identify any pathology. Some pathology, particularly optic nerve hypoplasia, needs to be carefully looked for in a child. Treatment may be inappropriately and unsuccessfully commenced if such visually limiting pathology remains undetected.

(3) Cycloplegic refraction and corrective prescription if indicated. Amblyopia cannot be diagnosed unless any significant refractive error has been corrected.

(4) Rechecking visual acuity with any prescribed refractive correction in place. Some improvement in visual acuity can be expected with spectacles alone. There should be a period of adjustment into spectacles before retesting. Traditionally this adjustment period has been four to six weeks, but studies on refractive and strabismic amblyopia show this may be as long as 24 weeks (Moseley 2002). Definitions of amblyopia vary largely due to the fact that there is little evidence as to what constitutes normal vision on many commonly used tests at different ages. It may be defined by comparing the eyes (inter-ocular difference) or by looking at monocular visual acuity alone. We have elected to define amblyopia as vision worse than 6/9 on a Snellen-based test, 0.2 LogMAR, or its equivalent in one eye. 


\section{Description of the intervention/How the intervention might work}

Visual loss attributable to SDA can be severe. The aim of treatment is to maximize visual recovery without adversely affecting acuity in the better-seeing eye. The rationale for treatment is two-fold: to provide a good second eye should the better-seeing eye ever be visually compromised and to maximize stereopsis (binocular cooperation between the eyes). Untreated or unsuccessfully treated amblyopia may impact adult life. For individuals with amblyopia, the lifetime risk of serious visual impairment due to loss or damage of the better-seeing eye is estimated to be between $1.2 \%$ and $3.3 \%$ (Rahi 2002). In addition, there are implications for employment prospects and, therefore, income; the number of jobs barred to individuals with reduced vision increases with the severity of the deficit (Adams 1999).

\section{Stages of treatment}

(1) Correct the causative factor that is degrading the quality of the visual image (e.g. infantile cataract extraction, ptosis repair). In cases of early unilateral deprivation, correction must be undertaken in the first eight to 12 weeks of life if good visual acuity is to be obtained (Birch 1986; Birch 1988; Gregg 1992; Kanski 1994; McCulloch 1994; Taylor 1997)

(2) Prescribe any necessary refractive correction to maximize the quality of visual stimulation received by the child's amblyopic eye. Intraocular implants, contact lenses or both may be used after cataract surgery.

(3) Occlusion therapy. Occlusion forces the use of the amblyopic eye, stimulating the formation of functional connections in the brain (Boothe 2000).

\section{Occlusion regimen:}

Protocols and practices vary considerably. Duration of occlusion therapy ranges from an hour to more than six hours (full-time). Factors affecting the amount prescribed include the level of visual deficit, the age of the child and the likely waiting time to the next appointment. Follow-up is recommended at intervals of one week per year of age during periods of aggressive patching (Simon 1987). Occlusion can be stopped when visual acuity becomes equal in the two eyes or if no progress has been made after three months of good compliance with occlusion (Pratt-Johnson 2001). It has been recommended that children in this situation are monitored up to the age of visual maturity (approximately seven years of age) to ensure that amblyopia does not recur. Some periods of maintenance occlusion may be required during that time (Mein 1991).

The following have been used as additions to occlusion therapy, but appear not to be currently popular clinically:

(1) CAM visual stimulator: uses rotating high-contrast square wave gratings to stimulate the amblyopic eye.
(2) Pleoptics: employs after-images to encourage foveal fixation and normal projection in the amblyopic eye

\section{Types of occlusion:}

Atropine penalization and optical penalization (use of lenses to reduce the acuity) are other forms of occlusion that encourage use of the amblyopic eye by diminishing visual form. These treatments for amblyopia are being evaluated in other Cochrane reviews currently underway (Li 2007).

This review examined the role of total occlusion to form and light as an intervention for SDA. Total occlusion, also known as conventional occlusion, is usually achieved by means of an opaque, adhesive patch on the better-seeing eye. Less commonly, occlusive contact lenses are employed. As mentioned previously, bilateral SDA is rare and not usually treated with occlusion therapy and therefore was not considered in this review.

\section{Measuring outcomes}

In order to quantify amblyopia, visual acuity must be measured. Qualitative methods for assessing vision in preverbal children are based on the observation of their fixation patterns. These methods are often unreliable and require highly trained examiners (Wright 1986; Zipf 1976). Final visual acuity assessed using an age-appropriate test (Fulton 1978; Sebris 1987) is the most commonly used outcome from treatment. Tests vary in the use of optotypes (picture, letter, or symbol) and may be with or without crowding; crowded visual acuity tests are harder to perform but are more sensitive to amblyopia than uncrowded tests.

Developmental changes in young children complicate the evaluation of actual change in acuity from pre- to post-treatment. Alternative methods of measuring change have been suggested in an attempt to overcome this (Schmidt 1994; Stewart 2003), but we aimed to compare post-treatment visual acuity values (defining restoration of normal visual acuity as better than or equal to 6/9 on Snellen, or 0.2 LogMAR or its equivalent).

\section{Factors affecting outcome}

Compliance with therapy is critical for successful treatment but can often be difficult to achieve. Young children can become distressed by being restricted to reduced visual acuity and from the discomfort of wearing an adhesive patch. It has been suggested that, if possible, compliance should be monitored to more effectively measure response to treatment. Devices to objectively measure compliance have been developed (Awan 2005; Stewart 2005) but are not commonly used; clinicians still generally depend on parental reports. Other factors thought to affect treatment success are duration of visual deprivation and age at onset of therapy (Maurer 1989): the earlier the onset, the longer the duration and the later treatment is commenced, the worse the visual prognosis. 


\section{Harm from occlusion therapy}

Potential adverse effects from occlusion therapy include inducing amblyopia in the occluded eye, skin allergies, infections and/or corneal abrasions from contact lens wear, diplopia (double vision), and psychological effects (e.g. distress).

\section{Why it is important to do this review}

The reported success of treatment for SDA varies. There are studies reporting good levels of vision following early treatment (Gregg 1992; McCulloch 1994), but there is a lack of standardization and poor agreement among experts as to the optimum amount of occlusion needed to achieve good visual outcome. Commencing occlusion therapy in infants with very poor vision can be harrowing for the parents and stressful for the child. Realistic treatment goals are often poorly defined. It is thus necessary to establish the most effective occlusion regimen(s) for stimulus deprivation amblyopia and to define the degree of improvement that can be reasonably expected from this treatment.

\section{Types of interventions}

The following interventions were of interest:

- total occlusion by adhesive patch;

- total occlusion by occlusive contact lens;

- pleoptic treatment;

- partial occlusion (i.e. Bangerter filters);

- CAM visual stimulation.

The following comparisons were examined:

(1) total occlusion versus no occlusion;

(2) any means of total occlusion compared to another;

(3) any total occlusion plus pleoptic treatment versus total occlusion alone;

(4) any total occlusion plus CAM visual stimulator versus total occlusion alone;

(5) full-time occlusion (more than six hours / day) versus parttime occlusion (less than six hours / day);

(6) partial versus partial (e.g. two hours/day versus six hours/day)

\section{Types of outcome measures}

\section{Primary outcomes}

The primary outcome for this review was best-corrected visual acuity of the amblyopic eye, on an age-appropriate test, six months from cessation of occlusion.

Although not directly equivalent, we planned to convert Snellen data into a LogMAR equivalent for ease of interpretation and analysis.

Outcomes were to be dichotomized:

(1) Normal = better than or equal to 0.2 LogMAR, 6/9 Snellen or its equivalent.

(2) Residual deficit $=$ worse than 0.2 LogMAR.

Where possible, we planned to report mean values.

\section{Secondary outcomes}

The secondary outcomes for this review were:

(1) Visual acuity in the amblyopic eye at seven years of age or older.

(2) The proportion of the amblyopia deficit corrected (Stewart 2003).

(3) Any measure of stereoacuity (3-dimensional vision).

\section{Cost data}

We planned to summarize the comparative costs of treatment methods described in included trials. 


\author{
Adverse effects \\ We planned to summarize adverse effects related to treatment that \\ were reported in included trials: \\ Severe: occlusion amblyopia, contact lens-related problems (e.g. \\ infection, corneal abrasions), adverse psychological effects (e.g. \\ distress), treatment cessation due to poor compliance or failure to \\ attend, or diplopia. \\ Minor: allergy to patches.
}

\section{Quality of life measures}

We planned to summarize any reports on quality of life measures in the included trials.

\section{Follow up}

A minimum of six months' post-treatment follow-up was necessary for inclusion and analysis; any eligible studies with less follow-up were described.

\section{Search methods for identification of studies}

\section{Electronic searches}

We searched the Cochrane Central Register of Controlled Trials - CENTRAL (which contains the Cochrane Eyes and Vision Group Trials Register) in The Cochrane Library, MEDLINE, EMBASE and Latin American and Caribbean Literature on Health Sciences (LILACS). There were no date or language restrictions. The databases were last searched on 27 November 2007. See:Appendices for details of search strategies for each database.

\section{Searching other resources}

No manual searches were undertaken for this review but will be carried out if possible in future updates. Manual searches will include searching Web of Science for other studies that cite included trials, and searching bibliography of included trials.

\section{Data collection and analysis}

\section{Assessment of search results}

Two review authors independently assessed the titles and abstracts of all reports identified by the electronic searches as per the 'Criteria for considering studies for this review.' The reviewers were unmasked to the report authors, institutions and trial results during this assessment.

The abstracts were classified as (a) definitely include, (b) unsure and (c) definitely exclude. Full copies of those classified as (a) definitely include and (b) unsure were obtained and re-assessed. The studies were then classified as (1) included, (2) awaiting clarification and (3) excluded. A third reviewer resolved any disagreements. Authors of studies classified as (2) awaiting assessment were contacted for further clarification. Details of studies identified by both reviewers as (3) excluded were documented in the relevant section of the review.

\section{Methods for future updates}

If any randomized or quasi-randomized trials are identified in future updates of this review we will adopt the following methods.

\section{Assessment of methodological quality}

Two review authors will independently assess the sources of systematic bias in trials according to methods set out in section 6 of the Cochrane Handbook for Systematic Reviews of Interventions (Higgins 2006). The following parameters will be considered:

- quality of allocation concealment (selection bias);

- method of randomization;

- completeness of follow-up (i.e. attrition bias) - how many participants were lost to follow-up, how they were accounted for, whether follow-up rates for groups were similar;

- whether all participants were analyzed as randomized. If studies report that an intention-to-treat analysis (ITT) was performed, we will assess whether both a) participants where no outcome was collected, and b) those who only received some or none of their allotted treatment were included. We will only interpret a true ITT analysis to have been undertaken if both these criteria have been fulfilled.

- detection bias: whether assessment of outcome was concealed and if so, how adequately.

Each of the parameters will be graded as (A) Adequate or Yes, (B) Unclear or Not Reported, and (C) Inadequate or No. A third reviewer will resolve any disagreements. Masking of participants and care providers is not feasible in these trials and hence will not be used as a measure of quality. For trials categorized as (B) Unclear or Not Reported, the authors will be contacted for additional information. If the authors do not respond within four weeks, the reviewers assigned a grade to the trial based on the available information.

In addition to the parameters described above, other data will be extracted:

(1) Participants:

- numbers, age at onset and intervention, duration of stimulus deprivation, cause of stimulus deprivation, starting visual acuity, refractive correction;

- concomitant ocular pathology that may limit visual outcome (e.g. coloboma, optic nerve hypoplasia, retinal dystrophy). Studies including such participants will be subjected to a subgroup analysis;

- adjustment period into spectacle correction.

(2) Intervention: method of occlusion, regime, CAM, pleoptics. 
(3) Outcomes: test(s) used, length of follow up, if, when and how compliance assessed.

\section{Data extraction and management}

Two review authors will independently extract data for the primary and secondary outcomes onto paper data collection forms developed by the Cochrane Eyes and Vision Group. Discrepancies will be resolved by discussion. Primary investigators will be contacted for missing data. One review author will enter data into RevMan 4.2. A second review author will independently re-enter the data, using the double data-entry facility to check for inaccuracies.

\section{Measures of treatment effect}

Data analysis followed the guidelines in section 8 of the Cochrane Handbook for Systematic Reviews of Interventions (Deeks 2006). For dichotomous outcomes, summary odds ratio will be calculated for rarer outcomes or risk ratio for more frequent outcomes. Weighted mean difference will be reported for continuous outcomes, for example, for trials that have measured vision using LogMAR tests throughout the study.

\section{Unit of analysis issues}

Statistical input from the Cochrane Eyes and Vision Group Editorial Base will be obtained for analysis of trials with multiple treatment groups, cross-over trials and cluster randomized trials.

\section{Dealing with missing data}

We will contact the investigators for more information on missing data. If they're unable to provide additional information, we will seek input from the Cochrane Eyes and Vision Group Editorial Base for guidance.

\section{Assessment of heterogeneity}

Forest plots will be examined for overlap of $95 \%$ confidence intervals of effect estimates for visual assessment of heterogeneity between effect estimates of included trials. I-square value will be calculated and the chi-square test for heterogeneity will be conducted. I-square values more than $50 \%$ will be considered substantial heterogeneity.

\section{Data synthesis (meta-analysis)}

If no statistical heterogeneity was detected or if there was no clinical heterogeneity within the trials, the results will be combined in a meta-analysis using a fixed-effect model. If there is statistical heterogeneity in the absence of clinical heterogeneity, a summary measure will be computed using a random effects model if I-square value is below $50 \%$. In case of substantial statistical or clinical heterogeneity (I-square value greater than $50 \%$ ), study results will not combined, but will be presented in a tabulated or narrative summary.

\section{Investigation of heterogeneity}

If sufficient numbers of trials are available and are stratified prior to randomization, the following subgroups will be explored:

- participants without any co-existing ocular pathology (that might be expected to limit visual prognosis) were analyzed separately from those with other pathology.

- participants with stimulus deprivation amblyopia associated with a unilateral congenital cataract were compared to stimulus deprivation amblyopia associated with any other unilateral etiology.

\section{Sensitivity analysis}

Sensitivity analyses will be conducted, if appropriate, to determine the size and direction of effect when excluding the following:

- Outcomes measured on uncrowded vision tests

- Studies where any parameter has been graded 'C' or 'No'

- Excluding unpublished studies or industry-funded studies

\section{RES U L T S}

\section{Description of studies}

See: Characteristics of excluded studies.

\section{Results of the search}

The electronic searches conducted in 2004 identified 799 abstracts and titles of which seven appeared to be randomized controlled trials (RCTs) of interventions for amblyopia. Of these, three trials evaluated conventional occlusion therapy but did not include patients with SDA (Clarke 2003; Holmes 2003; Repka 2003). There were four studies (Keith 1980; Mehdorn 1981; Nyman 1983; Tytla 1981) on the CAM visual stimulator but after reading the full text of the studies and contacting the authors where necessary, it became apparent that only one trial (Nyman 1983) had included participants with SDA and the data relevant to this review were no longer available. All seven trials were therefore excluded (see table: Characteristics of excluded studies).

Full text copies of 25 references were obtained because the initial search information was insufficient to establish whether the studies were eligible for inclusion or not. This was either because the title only was available, the abstract was unclear or the abstract or study was written in a language other than English. After further perusal or translation, all studies were found to be ineligible and 
were excluded. Reasons for exclusion have been documented in the table: Characteristics of excluded studies.

An updated search was done in November 2007 which yielded an additional 53 reports of studies. One RCT including five patients with SDA was found, but this investigated the effectiveness of an educational program on the predictors of noncompliance to occlusion therapy (Loudon 2006). Five additional RCTs investigated occlusion therapy (Hertle 2007; Repka 2007; Stankovic 2007; Stewart 2007; Wallace 2006), but these only included strabismic and/or anisometropic amblyopia. Thus, the search did not identify any new trials which met the inclusion criteria for the review.

\section{Risk of bias in included studies}

We found no randomized or quasi-randomized trials eligible for inclusion in the review.

\section{Effects of interventions}

None of the studies identified in the searches were eligible for inclusion, highlighting a significant gap in the existing evidence for the treatment of stimulus deprivation amblyopia. In order to provide the reader with some insight into the basis for current practice, some of the non-randomized studies identified incidentally in the searches and others already known to the authors are discussed below.

\section{I S C U S S I O N}

Since no RCTs were found, other relevant studies already known to the authors or identified in the searches have been described in order to comment on current practice. It is important to note that these were not systematically searched for, thus do not represent a systematic/comprehensive summary of existing evidence.

Treatment for strabismic and/or anisometropic amblyopia has recently been subject to more rigorous scrutiny in high quality RCTs. These studies have helped clarify the level at which amblyopia treatment works and have provided useful information as to which occlusion regimens may work most effectively (Clarke 2003; Holmes 2003; Repka 2003; Stewart 2007). However, SDA is nearly always specifically excluded from these randomized or even from non-randomized trials. This is because SDA is generally accepted, not only to be more severe and therefore more resistant to treatment (Kanski 1994; Taylor 1997), but may also (based on animal studies) have a different pathophysiological mechanism from the other types (Mitchell 2002).

Treatment for SDA is confounded by many factors: possible coexisting pathology, the young age of the patient, limitations of clinical tests. These make it very difficult to quantify the degree of visual deficit, to establish how much is attributable to amblyopia and whether or not it is responding to treatment. The age of the patient and the severity of visual loss can also result in poor compliance with treatment and significant stress and distress for both parents and child. There is also a dearth of evidence as to what outcomes must be realistically expected.

Current evidence of treatment is largely derived from non-randomized studies of SDA caused by unilateral congenital cataract. A brief overview of some of these data is summarized below.

\section{Occlusion type}

The majority of studies we came across described the use of total or conventional occlusion for the treatment of SDA. Although it is not without disadvantages in terms of discomfort, it is relatively easy to control the dosage of treatment and is without the more complex side effects of occlusive contact lenses. One RCT(Nyman 1983) looked at the additional effect of CAM stimulation compared to total occlusion alone, but the data for SDA could not be isolated from the data for the other types of amblyopia. This treatment, though prevalent in the 1980s, has largely disappeared from current practice possibly due to the lack of evidence of longterm benefit and its time implications for both the patient and the clinician.

\section{Occlusion regimens and treatment outcomes}

Current practice generally favors aggressive patching in early life based on the knowledge that the visual system is much more sensitive to change at this age. Mayer 1989 reports a negative correlation between the number of hours patched and inter-ocular difference in acuity. Intensive or aggressive patching varies widely from a minimum of six hours per day to as much as $100 \%$ of waking hours. Birch 1988 reported 53\% achieved a visual acuity of $20 / 80(6 / 24)$ or better with this treatment. Lundvall 2002 found $20 \%$ attained visual acuity of $0.1(6 / 7.5)$ or better and Drummond 1989 reported 43\% achieved VA better than 20/50 (6/9). Robb 1987 found 46\% achieved visual acuity of at least 20/70 (6/18). Although by no means comprehensive, this brief summary highlights the variable 'success' rate and also the different ways in which results can be categorized. This and other dissimilarities in study methodologies make it impossible to meaningfully compare results among these studies.

Less intense occlusion regimens, while being easier to execute, have been advocated because they promote more binocular interaction and stereoacuity. Brown 1999 reported good visual and binocular results with occlusion of one hour per day per month of age for the first six months of life. A more recent study (Stewart 2007) reported no difference in outcomes between patching for 
six hours and 12 hours a day in children with strabismic and/or anisometropic amblyopia.

\section{Compliance}

Many, if not all, papers on occlusion treatment for SDA highlight the necessity of good compliance in order to achieve a satisfactory outcome. Unfortunately, compliance in treating SDA is extremely difficult to achieve. While it may not be too surprising that a treatment that visually compromises a child by means of an adhesive patch is not easy to deliver, justification of such a treatment must carefully consider any potential harm alongside evidence of benefit. In a culture where justifying intervention is increasingly required, the current absence of clear evidence of effectiveness in this area is concerning.

Compliance also effects interpretation of the dose-response treatment effect. Some studies on refractive and strabismic amblyopia have used objective methods to monitor how much occlusion is actually worn (Awan 2005; Loudon 2002; Stewart 2005). These show that the prescribed amount of occlusion is not always achieved and that lower doses of occlusion can be as effective as the more intense occlusion regimens. Studies have also used objective measurements of compliance to identify parental and demographic characteristics associated with poor compliance with occlusion therapy (Loudon 2006). To date, such information for SDA is lacking.

\section{A U THORS' CONCLUSIONS}

\section{Implications for practice}

It is not possible to draw reliable conclusions from the available data since the study designs either do not compare treatment strategies or are subject to significant bias in the selection of participants for particular treatments. In addition, the variation between studies in treatment delivery and outcome measurement prevents the comparison or combination of results.

The general trend in practice (based on the proportion of papers we found reporting this treatment) appears to favor the more intensive occlusion therapy regimen to attain better visual outcomes, although this has not been thoroughly tested and has been linked to problems with compliance. There is some evidence that less intense treatment may have favorable results. The difficulties associated with treatment, the demand on resources and the potential impact on the patient need to be considered carefully against the current absence of real evidence of treatment benefit for SDA. It is currently difficult to objectively advise parents or to formulate evidence-based guidelines for the management of SDA. It remains uncertain what to realistically expect from treatment for SDA and how to best achieve this.

\section{Implications for research}

There is a clear and pressing need for higher quality studies in the management of SDA. While occlusion therapy currently remains the mainstay of treatment, withdrawing it for a time in the context of a RCT may be deemed unethical; it must also be studied whether it is worth continuing an intense and potentially traumatic treatment which does not have a clearly defined end-point or a strong evidence of effectiveness.

Unsuccessful treatment ultimately results in the same outcome as no treatment - blindness or partial sight in one eye. Exposure to treatment also carries with it the potential for harm, thus, future studies on treatment for SDA should report treatment effect and accurately measure any potential physical, emotional or psychological harm.

Specific questions that need to be addressed in prospective, randomized studies (with appropriate pre-randomization stratification for any subgroup analyses) are:

- duration of stimulus deprivation;

- the level of vision that can be realistically achieved; effect of age at onset and density of visual;

- optimum occlusion regimen occlusion;

- duration of treatment necessary to achieve optimum benefit;

- potential adverse effects from treatment;

- factors associated with satisfactory and unsatisfactory outcomes.

\section{ACKNOWLEDGEMENTS}

The Cochrane Eyes and Vision Group devised the search strategies for this review and carried out electronic searches.

We thank Richard Harrad, Catey Bunce, Sue Elliott and Suzanne Brodney-Folse for their peer review comments throughout the review process. We are also grateful to Milan Mathew for his guidance during the protocol stage. In addition, we thank Ruthy Acosta for her assistance with articles written in Spanish. 


\section{R E F E R E N C E S}

\section{References to studies excluded from this review}

Arruga 1966 \{published data only\}

Arruga A. Occlusion therapy in children. International

Ophthalmology Clinics 1966;6(3):435-52.

Clarke 2003 \{published data only\}

Clarke MP, Wright CM, Hrisos S, Anderson JD, Henderson J, Richardson SR. Randomised controlled trial of treatment of unilateral visual impairment detected at preschool vision screening. BMJ 2003;327(7426):1251.

Cramer 1966 \{published data only\}

Cramer FE, Lamela N, Luqui Lagleyze J, Corsellas A. Use of the electronic flash in the pleoptic treatment of amblyopias [Uso del flash electronico en el tratamiento pleoptico de las ambliopias]. Arquivos brasileiros de oftalmologia 1966;29(3): 83-8.

Cuppers 1967 \{published data only\}

Cuppers C. Effects of pleoptic therapy with special consideration of permanent results. II [Ergebnisse der pleoptischen Therapy unter besonderer Berucksichtigung der Dauerresultate. II]. Documenta Ophthalmologica 1967; 23:570-605.

Fletcher 1969a \{published data only\}

Fletcher MC, Silverman SJ, Boyd J, Callaway M. Biostatistical studies. Comparison of the management of suppression amblyopia by conventional patching, intensive hospital pleoptics, and intermittent office pleoptics. American Orthoptic Journal 1969;19:40-7.

Fletcher 1969b \{published data only\}

Fletcher MC, Abbott W, Girard LJ, Guber D, Silverman SJ, Tomlinson E, et al.Biostatistical studies. Results of biostatistical study of the management of suppression amblyopia by intensive pleoptics versus conventional patching. American Orthoptic Journal 1969;19:8-30.

Flynn 1967 \{published data only\}

Flynn JT, Vereecken E. Effects of pleoptic therapy with special consideration of permanent results. I. Documenta Ophthalmologica 1967;23:550-69.

Flynn 1968 \{published data only\}

Flynn JT. Results with the use of pleoptics in the treatment of amblyopia. Southern Medical Journal 1968;61(11): 1169-71.

Funghini 1973 \{published data only\}

Funghini G. Interest of orthoptic and pleoptic treatment [Linteresse del trattamento ortottico e pleottico]. Minerva Medica 1973;64(69):3612-5.

Hertle 2007 \{published data only\}

* Hertle RW, Scheiman MM, Beck RW, Chandler DL, Bacal DA, Birch E, et al.Stability of visual acuity improvement following discontinuation of amblyopia treatment in children aged 7 to 12 years. Archives of Ophthalmology 2007;125(5):655-9.
Holmes 2003 \{published data only\}

Holmes JM, Kraker RT, Beck RW, Birch EE, Cotter SA, Everett DF, et al.A randomized trial of prescribed patching regimens for treatment of severe amblyopia in children. Ophthalmology 2003;110(11):2075-87.

Iacobucci 1977 \{published data only\} Iacobucci I. Patching program for treatment of amblyopia. Journal of Pediatric Ophthalmology 1977;14(1):7-11.

Keith 1980 \{published data only\} Keith CG, Howell ER, Mitchell DE, Smith S. Clinical trial of the use of rotating grating patterns in the treatment of amblyopia. British Journal of Ophthalmology 1980;64(8): 597-606.

Kuming 1982 \{published data only\} Kuming BS, Klugman M. The value of CAM visual stimulation. South African Archives of Ophthalmology 1982; 9(3-4):65-70.

Lang 1965 \{published data only\}

Lang J. "Increasing occlusion" in the treatment of amblyopia with eccentric fixation [Die "Ansteigeokklusion" zur Behandlung der Amblyopie mit exzentrischer Fixation]. Ophthalmologica 1965;149(6):456-62.

Lennerstrand 1983 \{published data only\} Lennerstrand G. Recent advances in the management of amblyopia. International Rehabilitation Medicine 1983;5 (3):128-31.

Loudon 2006 \{published data only\} Loudon SE, Fronius M, Looman CW, Awan M, Simonsz $\mathrm{B}$, van der Maas PJ, et al.Predictors and a remedy for noncompliance with amblyopia therapy in children measured with the occlusion dose monitor. Investigative Ophthalmology \& Visual Science 2006;47(10):4393-400.

Mackensen 1965 \{published data only\} Mackensen G, Kroner B, Postic G. On the change of eccentric fixation under occlusion treatment [Zur Anderung der exzentrischen Fixation unter der Okklusionsbehandlung]. Klinische Monatsblätter für Augenheilkunde 1965;147(2):213-30.

Malik 1970 \{published data only\} Malik SR, Gupta AK, Grover VK. Occlusion therapy in amblyopia with eccentric fixation. British Journal of Ophthalmology 1970;54(1):41-5.

Mehdorn 1981 \{published data only\} Mehdorn E, Mattheus S, Schuppe A, Klein U, Kommerell $\mathrm{G}$. Treatment for amblyopia with rotating gratings and subsequent occlusion: a controlled study. International Ophthalmology 1981;3(3):161-6.

Nyman 1983 \{published data only\} Nyman KG, Singh G, Rydberg A, Fornander M. Controlled study comparing CAM treatment with occlusion therapy. Britsh Journal of Ophthalmology 1983;67(3):178-80. 
Pistelka 1973 \{published data only\}

Pistelka Z. In-patient pleoptic and orthoptic treatment and its results in pre-school children [Ustavni pleoptickoortopticka lecba a jeji vysledky u deti predskolniho veku]. Ceskoslovenska Oftalmologie 1973;29(1):41-9.

Priegnitz 1965 \{published data only\}

Priegnitz F, Zimmer R. On the occlusive treatment of amblyopia with eccentric fixation [Zur Okklusivbehandlung von Amblyopien mit exzentrischer Fixation]. Das Deutsche Gesundheitswesen 1965;20(42):1915-8.

Repka 2003 \{published data only\}

Repka MX, Beck RW, Holmes JM, Birch EE, Chandler DL, Cotter SA, et al.A randomized trial of patching regimens for treatment of moderate amblyopia in children. Archives of Ophthalmology 2003;121(5):603-11.

Repka 2007 \{published data only\}

Repka MX, Melia M, Eibschitz-Tsimhoni M, London, R, Magoon E, Pediatric Eye Disease Investigator Group. The effect on refractive error of unilateral atropine as compared with patching for the treatment of amblyopia. Journal of AAPOS : the Official Publication of the American Association for Pediatric Ophthalmology and Strabismus / American Association for Pediatric Ophthalmology and Strabismus 2007; 11(3):300-2.

Schor 1983 \{published data only\}

Schor C, Wick B. Rotating grating treatment of amblyopia with and without eccentric fixation. Journal of the American Optometric Association 1983;54(6):545-9.

Shroff 1983 \{published data only\} Shroff AP, Billore OP, Dubey AK, Antani PR. A combined approach by spectacle correction, occlusion and active pleoptic treatment in management of amblyopia. Indian Journal of Ophthalmology 1983;31(5):568-9.

Stankovic 2007 \{published data only\}

Stankovic B, Milenkovic S. Continuous full-time occlusion of the sound eye vs full-time occlusion of the sound eye periodically alternating with occlusion of the amblyopic eye in treatment of amblyopia: a prospective randomized study. European Journal of Ophthalmology 2007;17(1):11-9.

Stewart 2007 \{published data only\}

Stewart CE, Stephens DA, Fielder AR, Moseley MJ, ROTAS Cooperative. Objectively monitored patching regimens for treatment of amblyopia: randomised trial. British Medical Journal 2007;335(7622):707.

Stojcevska 1975 \{published data only\}

Stojcevska V. Pleoptic orthoptic treatment of functional amblyopia [Pleopticko ortopticko lekuvanje na funkcionalnite amblyopii]. Godişen zbornik na Medicinskiot fakultet vo Skopje 1975;21:201-5.

Tomlinson 1973 \{published data only\} Tomlinson E, Jablonski M. Results of modified pleoptic therapy in eccentric fixation. American Orthoptic Journal 1973;23:60-4.
Tommila 1969 \{published data only\}

Tommila V, Nordman E. Late results of pleoptic treatment. British Journal of Ophthalmology 1969;53(11):769-72.

Tommila 1974 \{published data only\}

Tommila V. Occlusion therapy of amblyopia [Amblyopian peittohoito]. Duodecim 1974;90(4):295-304.

Tytla 1981 \{published data only\} Tytla ME, Labow-Daily LS. Evaluation of the CAM treatment for amblyopia: A controlled study. Investigative Ophthalmology \& Visual Science 1981;20(3):400-6.

Veronneau 1974 \{published data only\} Veronneau Troutman S, Dayanoff SS, Stohler T, Clahane AC. Conventional occlusion vs. pleoptics in the treatment of amblyopia. American Journal of Ophthalmology 1974;78 (1):117-20.

Wallace 2006 \{published data only\} Wallace DK, Pediatric Eye Disease Investigator Group, Edwards AR, Cotter SA, Beck RW, Arnold RW, et al.A randomized trial to evaluate 2 hours of daily patching for strabismic and anisometropic amblyopia in children. Ophthalmology 2006;113(6):904-12.

Widder 1967 \{published data only\} Widder W. Experiences with occlusion therapy in the 5th-7th years of age [Erfahrungen mit der Okklusionstherapie im 5.-7. Lebensjahr]. Klinische Monatsblätter für Augenheilkunde 1967;151(5):684-702.

Zang 1988 \{published data only\} Zang YF, Guo JQ, Liu JQ. Occlusion therapy for amblyopia and stereopsis. Chinese Medical Journal 1988;101(10): 719-22.

\section{Additional references}

Adams 1999

Adams GG, Karas MP. Effect of amblyopia on employment prospects. British Journal of Ophthalmology 1999;83(3):380.

Awan 2005

Awan M, Proudlock FA, Gottlob I. A randomized controlled trial of unilateral strabismic and mixed amblyopia using occlusion dose monitors to record compliance. Investigative Ophthalmology and Vision Science 2005;46(4):1435-9.

Awaya 1973

Awaya S, Miyake Y, Imaizumi Y, Shinose Y, Kanda T, Komoru K. Amblyopia in man, suggestive of stimulus deprivation amblyopia. Japanese Journal of Ophthalmology 1973;17:69-82.

Birch 1986

Birch EE, Stager DR, Wright W W. Grating acuity development after early surgery for congenital unilateral cataract. Archives of Ophthalmology 1986;104:1783-7.

\section{Birch 1988}

Birch E E, Stager D. Prevalence of good visual acuity following surgery for congenital unilateral cataract. Archives of Ophthalmology 1988;106:40-3. 
Boothe 2000

Boothe RG, Fulton AB. Amblyopia. In: Albert DM, Jakobiec FA editor(s). Principles and Practice of Ophthalmology. 2nd Edition. WB Saunders Co, 2000.

\section{Brown 1999}

Brown SM, Archer S, Del Monte MA. Stereopsis and binocular vision after surgery for unilateral infantile cataract. Journal of American Academy of Pediatric Ophthalmology and Strabismus 1999;3(2):109-113.

\section{Brown 2000}

Brown SA, Weih LM, Fu CL, Dimitrov P, Taylor HR, McCarty CA. Prevalence of amblyopia and associated refractive errors in an adult population in Victoria, Australia. Ophthalmic Epidemiology 2000;7(4):249-58.

\section{Buch 2001}

Buch H, Vinding T, La Cour M, Nielsen NV. The prevalence and causes of bilateral and unilateral blindness in an elderly urban Danish population The Copenhagen City Eye Study. Acta Ophthalmologica Scandinavica 2001;79(5): 441-9.

Dandona 2003

Dandona R, Dandona L. Childhood blindness in India: a population based perspective. British Journal of Ophthalmology 2003;87(3):263-5.

\section{Deeks 2006}

Deeks JJ, Higgins JPT, Altman DG, editors. Analysing and presenting data. Cochrane Handbook for Systematic Reviews of Interventions 4.2.6 [updated September 2006; Section 8. In: The Cochrane Library, Issue 4, 2006. Chichester, UK: John Wiley \& Sons, Ltd.

Dray 2002

Dray JP, Leibovitch I. Congenital ptosis and amblyopia: a retrospective study of 130 cases. Journal of Pediatric Ophthalmology \& Strabismus 2002;39(4):222-5.

Drummond 1989

Drummond GT, Scott WE, Keech RV. Management of monocular congenital cataracts. Archives of Ophthalmology 1989;107(1):45-51.

\section{Duke-Elder 1973}

Duke-Elder S, Wybar K. Ocular motility and strabismus. In: Duke-Elder S editor(s). System of Ophthalmology. St. Louis, Missouri: C V Mosby Co, 1973.

Enoch 1983

Enoch J, Hamer R. Image size correction of the unilateral aphakic infant. Ophthalmic Paediatrics and Genetics 1983;2: $153-65$.

Fanz 1958

Fanz RL. Pattern vision in young infants. Psychological Research 1958;8:43-7.

\section{Ferrone 1994}

Ferrone PJ, de Juan E Jr. Vitreous hemorrhage in infants. Archives of Ophthalmology 1994;112(9):1185-9.

Fulton 1978

Fulton AB, Manning KA, Dobson V. A behavioral method for efficient screening of visual acuity in young infants. II.
Clinical application. Investigative Ophthalmology \& Vision Science 1978;17(12):1151-7.

\section{Glanville 2006}

Glanville JM, Lefebvre C, Miles JN, Camosso-Stefinovic J. How to identify randomized controlled trials in MEDLINE: ten years on. Journal of the Medical Library Association 2006; 94(2):130-6

\section{Gregg 1992}

Gregg FM, Parks M. Stereopsis after congenital cataract extraction. American Journal of Ophthalmology 1992;114: 314-7.

\section{Gusek 2000}

Gusek Schneider GC, Martus P. Stimulus deprivation amblyopia in human congenital ptosis: a study of 100 patients. Strabismus 2000;8(4):261-70.

\section{Harwerth 1990}

Harwerth RS, Smith EL 3rd, Crawford ML, von Noorden GK. Behavioral studies of the sensitive periods of development of visual functions in monkeys. Behavioural Brain Research 1990;41(3):179-98.

\section{Higgins 2006}

Higgins JPT, Green S, editors. Assessment of study quality. Cochrane Handbook for Systematic Reviews of Interventions 4.2.6 [updated September 2006; Section 6. In: The Cochrane Library, Issue 4, 2006. Chichester, UK: John Wiley \& Sons, Ltd.

Hillis 1983

Hillis A, Flynn JT, Hawkins BS. The evolving concept of amblyopia: a challenge to epidemiologists. American Journal of Epidemiology 1983;118(2):192-205.

\section{Hockfield 1998}

Hockfield S, Lombroso PJ. Development of the cerebral cortex: IX Cortical development and experience: I. Journal of the American Academy of Child and Adolescent Psychiatry 1998;37(9):992-3.

\section{Kanski 1994}

Kanski JJ. Clinical Ophthalmology. 3rd Edition. Oxford, UK: Butterworth Heinemann, 1994.

\section{Kvarnstrom 2001}

Kvarnstrom G, Jakobsson P Lennerstrand G. Visual screening of Swedish children: an ophthalmological evaluation. Acta Ophthalmologica Scandinavica 2001;79(3): $240-4$.

Li 2007

Li T, Shotton K, Hillis A, Flynn J, Coutu J. Conventional occlusion versus pharmacologic penalization for amblyopia. Cochrane Database of Systematic Reviews 2007, Issue 2. [Art. No.: CD006460. DOI: 10.1002/14651858.CD006460]

\section{Loudon 2002}

Loudon SE, Polling JR, Simonsz HJ. A preliminary report about the relation between visual acuity increase and compliance in patching therapy for amblyopia. Strabismus 2002;10(2):79-82. 


\section{Lundvall 2002}

Lundvall A, Kugelberg U. Outcome after treatment of congenital unilateral cataract. Acta Ophthalmologica Scandanavica 2002;80(6):588-92.

\section{Maurer 1989}

Maurer D, Lewis TL, Brent HP. The effects of deprivation on human visual development: studies of children treated for cataracts. In: Morrison FJ, Lord C, Keating DP editor (s). Applied Developmental Psychology Vol 3: Psychological Development in Infancy. San Diego, CA: Academic Press, 1989:39-227.

\section{Mayer 1989}

Mayer DL, Moore B, Robb RM. Assessment of vision and amblyopia by preferential looking tests after early surgery for unilateral congenital cataracts. Journal of Pediatric Ophthalmology \& Strabismus 1989;26(2):61-8.

\section{McCulloch 1994}

McCulloch DL, Skarf B. Pattern reversal visual evoked potentials following early treatment of unilateral, congenital cataract. Archives of Ophthalmology 1994;112:510-8.

\section{Mein 1991}

Mein J, Trimble R. Diagnosis and Management of Ocular Motility Disorders. 2nd Edition. Oxford, UK: Blackwell Scientific Publications, 1991.

\section{Mitchell 2002}

Mitchell DE, MacKinnon S. The present and potential impact of research on animal models for clinical treatment of stimulus deprivation amblyopia. Clinical \& Experimental Optometry 2002;85(1):5-18.

\section{Moseley 2002}

Moseley M, Neufield M, McCarry B, Charnock A, McNamara R, Rice T, et al.Remediation of refractive amblyopia by optical correction alone. Ophthalmology and Physiological Optics 2002;22:296-9.

\section{Newman 2000}

Newman DK, East MM. Prevalence of amblyopia among defaulters of preschool vision screening. Ophthalmic Epidemiology 2000;7(1):67-71.

\section{Pratt-Johnson 2001}

Pratt-Johnson JA, Tillson G. Management of Strabismus and Amblyopia: A Practical Guide. 2nd Edition. New York, USA: Thieme, 2001.

\section{Rahi 2002}

Rahi J, Logan S, Timms C, Russell Eggitt I, Taylor D. Risk, causes, and outcomes of visual impairment after loss of vision in the non-amblyopic eye: a population-based study. Lancet 2002;360(9333):597-602.

\section{Robb 1987}

Robb RM, Mayer DL, Moore BD. Results of early treatment of unilateral congenital cataracts. Journal of Pediatric Ophthalmology \& Strabismus 1987;24(4):178-81.

\section{Schmidt 1994}

Schmidt PP. Vision screening with the RDE stereotest in pediatric populations. Optometry \& Vision Science 1994;71 (4):273-81.

\section{Schulz 1982}

Schulz E. [Amblyopia and refractive error in patients who suffered from eyelid haemangioma in early childhood [Deprivationsamblyopie und Refraktionsanomalie bei fruhkindlichen Lidhamangiomen]. Klinische Monatsblätter für Augenheilkunde 1982;181(3):192-4.

\section{Sebris 1987}

Sebris S, Dobson V, Macdonald M, Teller DY. Acuity cards for visual acuity assessment of infants and children in clinical settings. Clinical Vision Science 1987;2:45-58.

\section{Shotton 2005}

Shotton K, Powell C, Voros G. Interventions for refractive amblyopia. Cochrane Database of Systematic Reviews 2005, Issue 1. [Art. No.: CD005137. DOI: 10.1002/ 14651858.CD005137]

\section{Shotton 2008}

Shotton K, Elliott $S$. Interventions for strabismic amblyopia. Cochrane Database of Systematic Reviews 2008, Issue 2. [Art. No.: CD006461. DOI: 10.1002/14651858.CD006461]

Simon 1987

Simon JW, Parks MM, Price EC. Severe visual loss resulting from occlusion therapy for amblyopia. Journal of Pediatric Ophthalmology and Strabismus 1987;24(5):244-6.

\section{Stewart 2003}

Stewart CE, Moseley MJ, Fielder A. Defining and measuring treatment outcomes in unilateral amblyopia. British Journal of Ophthalmology 2003;87:1229-31.

\section{Stewart 2005}

Stewart CE, Fielder AR, Stephens DA, Moseley MJ, MOTAS Cooperative. Treatment of unilateral amblyopia: factors influencing visual outcome. Investigative Ophthalmology \& Vision Science 2005;46(9):3152-60.

Taylor 1997

Taylor D, Hoyt C. Practical Pediatric Ophthalmology. 1st Edition. Oxford, UK: Blackwell Science, 1997.

Von Noorden 1973 von Noorden GK. Experimental amblyopia in monkeys Further behavioral observations and clinical correlations. Investigative Ophthalmology 1973;12(10):721-6.

\section{Von Noorden 1981}

Von Noorden GK. New clinical aspects of stimulus deprivation amblyopia. American Journal of Ophthalmology 1981;92(3):416-21.

\section{Wiesel 1963}

Wiesel TN, Hubel DH. Comparison of the effects of unilateral and bilateral eye closure on cortical unit responses in kittens. Journal of Neurophysiology 1963;28:1029-40.

\section{Wright 1986}

Wright KW, Edelman PM, Walonker F, Yiu S. Reliability of fixation preference testing in diagnosing amblyopia. Archives of Ophthalmology 1986;104(4):549-53.

\section{Zipf 1976}

Zipf FR. Binocular fixation pattern. Archives of Ophthalmology 1976;94:401-5.

* Indicates the major publication for the study 


\section{CHARACTERISTICS OF STUDIES}

\section{Characteristics of excluded studies [ordered by study ID]}

\begin{tabular}{|c|c|}
\hline Study & Reason for exclusion \\
\hline Arruga 1966 & Review, not a clinical trial. \\
\hline Clarke 2003 & Randomized controlled trial but stimulus deprivation amblyopia not included \\
\hline Cramer 1966 & Not a randomized controlled trial. \\
\hline Cuppers 1967 & Retrospective case-control study*. \\
\hline Fletcher $1969 \mathrm{a}$ & Randomized controlled trial but stimulus deprivation amblyopia not included \\
\hline Fletcher $1969 \mathrm{~b}$ & Retrospective chart review. \\
\hline Flynn 1967 & Retrospective chart review. \\
\hline Flynn 1968 & Retrospective study. \\
\hline Funghini 1973 & Non-comparative study. \\
\hline Hertle 2007 & Randomized controlled trial but stimulus deprivation amblyopia not included \\
\hline Holmes 2003 & Randomized controlled trial but stimulus deprivation amblyopia not included \\
\hline Iacobucci 1977 & Review article. \\
\hline Keith 1980 & Trial of CAM vision stimulator; stimulus deprivation amblyopia not included \\
\hline Kuming 1982 & Before-after study with only 2 participants with stimulus deprivation amblyopia \\
\hline Lang 1965 & Case-series, non-comparative*. \\
\hline Lennerstrand 1983 & No participants with stimulus deprivation amblyopia. \\
\hline Loudon 2006 & $\begin{array}{l}\text { Randomized controlled trial on effectiveness of an educational program on the predictors for noncompliance } \\
\text { to occlusion therapy }\end{array}$ \\
\hline Mackensen 1965 & Case-series, non-comparative*. \\
\hline Malik 1970 & Cohort study. \\
\hline
\end{tabular}




\section{(Continued)}

\begin{tabular}{|c|c|}
\hline Mehdorn 1981 & Randomized controlled trial of CAM vision stimulator; stimulus deprivation amblyopia not included \\
\hline Nyman 1983 & $\begin{array}{l}\text { Trial of CAM vision stimulator; data on stimulus deprivation amblyopia included but could not be extrapolated } \\
\text { and no longer available }\end{array}$ \\
\hline Pistelka 1973 & Non-comparative study. \\
\hline Priegnitz 1965 & Non-comparative study*. \\
\hline Repka 2003 & Randomized controlled trial but stimulus deprivation amblyopia not included \\
\hline Repka 2007 & Randomized controlled trial but stimulus deprivation amblyopia not included \\
\hline Schor 1983 & Did not include participants with stimulus deprivation amblyopia \\
\hline Shroff 1983 & Non-comparative study. \\
\hline Stankovic 2007 & Randomized controlled trial but stimulus deprivation amblyopia not included \\
\hline Stewart 2007 & Randomized controlled trial but stimulus deprivation amblyopia not included \\
\hline Stojcevska 1975 & Non-comparative study*. \\
\hline Tomlinson 1973 & Non-comparative study. \\
\hline Tommila 1969 & Non-comparative study. \\
\hline Tommila 1974 & Review article. \\
\hline Tytla 1981 & Trial of CAM vision stimulator; stimulus deprivation amblyopia not included \\
\hline Veronneau 1974 & Used historical controls. \\
\hline Wallace 2006 & Randomized controlled trial but stimulus deprivation amblyopia not included \\
\hline Widder 1967 & Non-comparative study*. \\
\hline Zang 1988 & Non-comparative study. \\
\hline
\end{tabular}

* - full-text articles of these studies published in non-English languages were reviewed and are noted in this table. 


\section{DATA ANDANALYSES}

This review has no analyses.

\section{A P P E N D I CES}

\section{Appendix I. CENTRAL search strategy used for Issue 4, 2007}

\#1 MeSH descriptor Amblyopia

\#2 amblyop* or anopsi*

\#3 MeSH descriptor Pupil Disorders

\#4 MeSH descriptor Cataract

\#5 cataract* $^{*}$

\#6 MeSH descriptor Blepharoptosis

\#7 blepharoptosis or ptosis

\#8 MeSH descriptor Vitreous Hemorrhage

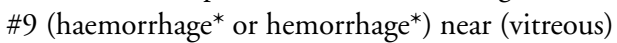

\#10 MeSH descriptor Hemangioma, Capillary

\#11 (hemangioma or haemangioma) near (capillary)

\#12 MeSH descriptor Aphakia

\#13 aphaki*

\#14 (stimul* or vision or visual or optical) near (deprivat*)

\#15 (scar* or opac* or degenerat*) near (cornea*)

$\# 16$ media next opacit*

\#17 (\#1 OR \#2 OR \#3 OR \#4 OR \#5 OR \#6 OR \#7 OR \#8 OR \#9 OR \#10 OR \#11 OR \#12 OR \#13 OR \#14 OR \#15 OR \#16)

\#18 MeSH descriptor Sensory Deprivation

\#19 patch* $^{*}$ or shield*

\#20 (stimul* or penalis*) near (optical ${ }^{*}$ )

$\# 21$ (stimul* or penalis*) near (vis*)

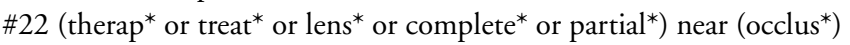

\#23 (therap* ${ }^{*}$ or treat* ${ }^{*}$ or lens* or complete* or partial*) near (pleoptic*)

\#24 (\#18 OR \#19 OR \#20 OR \#21 OR \#22 OR \#23)

\#25 (\#17 AND \#24)

\section{Appendix 2. MEDLINE search strategy used on OVID up to November 2007}

1 exp clinical trial/ [publication type]

2 (randomized or randomised).ab,ti.

3 placebo.ab,ti.

4 dt.fs.

5 randomly.ab,ti.

6 trial.ab,ti.

7 groups.ab,ti.

8 or/ $1-7$

9 exp animals/

10 exp humans/

119 not (9 and 10)

128 not 11

13 exp amblyopia/

Interventions for stimulus deprivation amblyopia (Review)

Copyright $\odot 2009$ The Cochrane Collaboration. Published by John Wiley \& Sons, Ltd. 
14 (amblyop\$ or anopsi\$).tw.

15 exp pupil disorders/

16 exp cataract/

17 cataract\$.tw.

18 exp blepharoptosis/

19 (blepharoptosis or ptosis).tw.

20 exp vitreous hemorrhage/

21 ((haemorrhage $\$$ or hemorrhage\$) adj3 vitreous).tw.

22 exp hemangioma,capillary/

23 ((hemangioma or haemangioma) adj3 capillary).tw.

24 exp aphakia/

25 aphaki\$.tw.

26 ((stimul\$ or vision or visual or optical) adj3 deprivat\$).tw.

27 ( (scar\$ or opac\$ or degenerat\$) adj3 cornea $\$)$.tw.

28 (media adj2 opacit\$).tw.

29 or/ $13-28$

30 exp sensory deprivation/

31 (patch $\$$ or shield $\$$ ).tw.

32 ((stimul\$ or penalis\$) adj3 optical\$).tw.

33 ((stimul\$ or penalis\$) adj3 vis\$).tw.

34 ((therap\$ or treat\$ or lens\$ or complete\$ or partial\$) adj3 occlus\$).tw.

35 ( (therap\$ or treat $\$$ or lens $\$$ or complete $\$$ or partial $\$$ ) adj3 pleoptic\$).tw.

36 or/30-35

3729 and 36

3812 and 37

The search filter for trials at the beginning of the MEDLINE strategy was from the published paper by Glanville (Glanville 2006).

\section{Appendix 3. EMBASE search strategy used on OVID up to November 2007}

1 exp randomized controlled trial/

2 exp randomization/

3 exp double blind procedure/

4 exp single blind procedure/

5 random $\$$.tw.

6 or/ $1-5$

7 (animal or animal experiment).sh.

8 human.sh.

97 and 8

107 not 9

116 not 10

12 exp clinical trial/

13 (clin\$ adj3 trial\$).tw.

14 ((singl\$ or doubl\$ or trebl\$ or tripl\$) adj3 (blind\$ or mask\$)).tw.

15 exp placebo/

16 placebo $\$$.tw.

17 random\$.tw.

18 exp experimental design/

19 exp crossover procedure/

20 exp control group/

21 exp latin square design/

22 or/12-21

2322 not 10

Interventions for stimulus deprivation amblyopia (Review)

Copyright @ 2009 The Cochrane Collaboration. Published by John Wiley \& Sons, Ltd. 
2423 not 11

25 exp comparative study/

26 exp evaluation/

27 exp prospective study/

28 (control\$ or prospectiv\$ or volunteer\$).tw.

29 or $/ 25-28$

3029 not 10

3130 not (11 or 23$)$

3211 or 24 or 31

33 exp amblyopia/

34 (amblyop\$ or anopsi\$).tw.

35 exp pupil disorders/

36 exp cataract/

37 cataract\$.tw.

38 exp blepharoptosis/

39 (blepharoptosis or ptosis).tw.

40 exp vitreous hemorrhage/

41 ((haemorrhage $\$$ or hemorrhage\$) adj3 vitreous).tw.

42 exp hemangioma,capillary/

43 ((hemangioma or haemangioma) adj3 capillary).tw.

44 exp aphakia/

45 aphaki\$.tw.

46 ((stimul\$ or vision or visual or optical) adj3 deprivat\$).tw.

47 ( (scar\$ or opac\$ or degenerat\$) adj3 cornea $\$)$.tw.

48 (media adj2 opacit\$).tw.

49 or/33-48

50 exp sensory deprivation/

51 (patch\$ or shield\$).tw.

52 ((stimul\$ or penalis\$) adj3 optical\$).tw.

53 ((stimul\$ or penalis\$) adj3 vis\$).tw.

54 ((therap\$ or treat $\$$ or lens $\$$ or complete $\$$ or partial\$) adj3 occlus\$).tw.

55 ((therap\$ or treat\$ or lens\$ or complete\$ or partial\$) adj3 pleoptic\$).tw.

56 or $/ 50-55$

5749 and 56

5832 and 57

\section{Appendix 4. LILACS search terms used on 3 December 2007}

amblyop\$ and stimul\$ or vis\$ or viz\$ optic $\$$ and deprivat $\$$

\section{WHAT'S NEW}

Last assessed as up-to-date: 26 November 2007. 


\begin{tabular}{l|l|l}
\hline Date & Event & Description \\
\hline 13 October 2008 & Amended & Converted to new review format. \\
\hline
\end{tabular}

\section{H I S T O R Y}

Protocol first published: Issue 1, 2005

Review first published: Issue 3, 2006

\begin{tabular}{lll}
\hline Date & Event & Description \\
\hline 27 November 2007 & New search has been performed & $\begin{array}{l}\text { An update search was done in November 2007; 6 RCTs } \\
\text { were excluded but no new trials were included in the } \\
\text { review }\end{array}$ \\
\hline 16 March 2006 & New citation required and conclusions have changed & Substantive amendment \\
\hline
\end{tabular}

\section{CONTRIBUTIONSOFAUTHORS}

Conceiving the review: AA

Designing the review: AA

Co-ordinating the review: AA, SSV

Data collection for the review

- Designing electronic search strategies: CEVG

- Undertaking searches: CEVG

- Screening search results: AA, CP, SSV

- Organizing retrieval of papers: AA, CP, SSV

- Screening retrieved papers against inclusion criteria: AA, CP, SSV, SH

- Appraising quality of papers: NA

- Extracting data from papers: NA

- Writing to authors of papers for additional information: NA

- Providing additional data about papers: NA

- Obtaining and screening data on unpublished studies: NA

Data management for the review

- Entering data into RevMan: NA

- Analysis of data: NA

Interventions for stimulus deprivation amblyopia (Review)

Copyright $\odot 2009$ The Cochrane Collaboration. Published by John Wiley \& Sons, Ltd. 
Interpretation of data

- Providing a methodological perspective: SSV, SH

- Providing a clinical perspective: AA, CP, SH

- Providing a policy perspective: AA, CP, SH

- Providing a consumer perspective: AA, CP, SH

Writing the review: AA, CP, SH, SSV

Providing general advice on the review: AA, CP, SH, SSV

Securing funding for the review: SSV

Performing previous work that was the foundation of the current study: AA, CP, SH

\section{DECLARATIONSOF INTEREST}

None known

\section{SOURCES OF SUPPORT}

\section{Internal sources}

- Michigan State University, Department of Neurology and Ophthalmology, USA.

- Brown University, USA.

- Johns Hopkins University, USA.

\section{External sources}

- Contract N01-EY-2-1003, National Eye Institute, National Institutes of Health, USA.

- Sightsavers International, UK.

- Christian Blind Mission, Germany.

\section{NDEX TERMS}

\section{Medical Subject Headings (MeSH)}

*Occlusive Dressings; Amblyopia [etiology; *therapy]; Blepharoptosis [complications]; Cataract [complications]; Treatment Outcome

\section{MeSH check words}

Child, Preschool; Humans; Infant 